\title{
Electron microscopy characterization of forest biomass soot as solar energy absorption material
}

L. B. López-Sosa ${ }^{1}$, M. González-Avilés ${ }^{2}$, M. Hernández-Ramírez ${ }^{3}$, A. Medina-Flores ${ }^{1}$, I. Santos-Ramos ${ }^{1}$ and J. Zárate-Medina ${ }^{1 *}$

1. Instituto de Investigación en Metalurgia y Materiales, Universidad Michoacana de San Nicolás de Hidalgo, Michoacán, México.

2. Programa académico de desarrollo sustentable, Universidad Intercultural Indígena de Michoacán, Michoacán, México.

${ }^{3}$ Facultad de Físico-Matemáticas, Universidad Michoacana de San Nicolás de Hidalgo, Michoacán, México.

* Corresponding author: jzaratemedina@gmail.com

Some carbon allotropes such as graphite, nanotubes, fullerenes, and especially graphene, have been used in recent years for thermosolar applications, mainly for the development of photothermal coatings that can be used in sustainable technologies [1]. However, little has been studied regarding organic materials derived from residential waste for this same application. The soot of forest biomass, which is a waste of combustion, has been reported as a material that can be used in photothermal applications for solar thermal technologies, and represents a sustainable strategy for the use of solid waste [2].

This paper shows the characterization of forest biomass soot from wood-saving stoves (Patsari @) [3], by Scanning Electron Microscopy (SEM), with a Jeol JSM 7600F Model field emission equipment, and Electron Microscopy of Transmission (TEM), using a Tecnai Supertwin Model equipment with field emission. The results show that soot is a material with carbon nanoparticles, with submicrometric agglomerates (Figure 1), consistent with other work on soot combustion [4]; after the collection of forest biomass soot, this material is very agglomerate, micrometric agglomerates are appreciated in the Figure 1(a). To de-agglomerate the soot, mechanical grinding was used with a planetary mill (PM100), at 350 rpm, for $8 \mathrm{~h}$. After the milling, small-sized agglomerates formed by soot nanoparticles can be observed. Figure 2 shows that the soot is a pseudoamorphous material, has certain crystalline traces associated with the (h, k, l) (002) plane, which is attributed to amorphous graphite, the graphitic planes have dislocations as shown in Figure 2 (d) [5]. The presence of this plane is linked to the sp2 bonds domain, due to its graphitic character. These carbon allotrope bonds have higher light absorption coefficients compared to known light absorbers [6], so their capacity as photothermal material is consistent with previous work [2]. The characterization by TEM analysis of the soot is a complementary technique for spectroscopic techniques and analysis of optical properties. In this case, the TEM analysis shows that forest biomass soot can be used as a coating in thermosolar technology, because an amorphous graphitic structure has been identified; and it is known that this material has solar energy absorption properties.

\section{References:}

[1] Chen \& Hu, Joule, 3, (2019), p. 1.

[2] López-Sosa, et al, Revista Mexicana de Ingeniería Química, 17(2), (2018), p. 651.

[3] Masera \& Berrueta, Energy for Sustainable Development, 9 (1), (2005), p. 25.

[4] Singh, et al, Electrochimica Acta, 264, (2018), p. 119.

[5] Pawlyta, et al, Carbon, 84, (2015), p. 479 
[6] Zhang, et al, Carbon, 109, (2016), p. 246.

[7] The authors acknowledge the UMSNH and CONACYT for the support to carry out this work
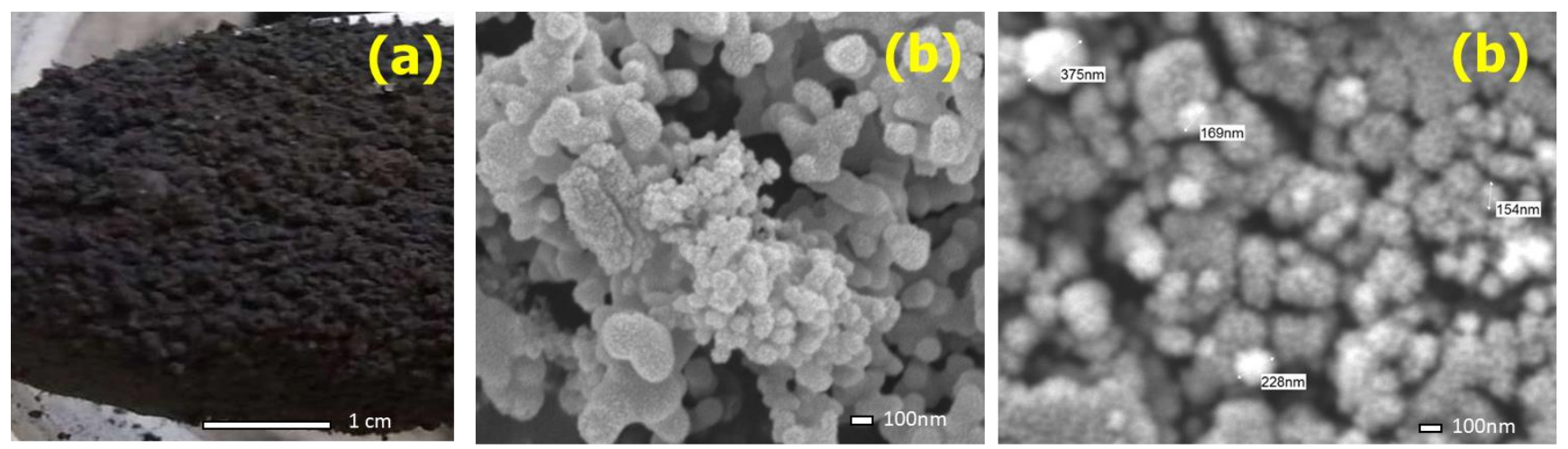

Figure 1. SEM: (a) forest biomass soot after collection (b) agglomerates of soot particles (c) submicron-sized agglomerates with variable sizes
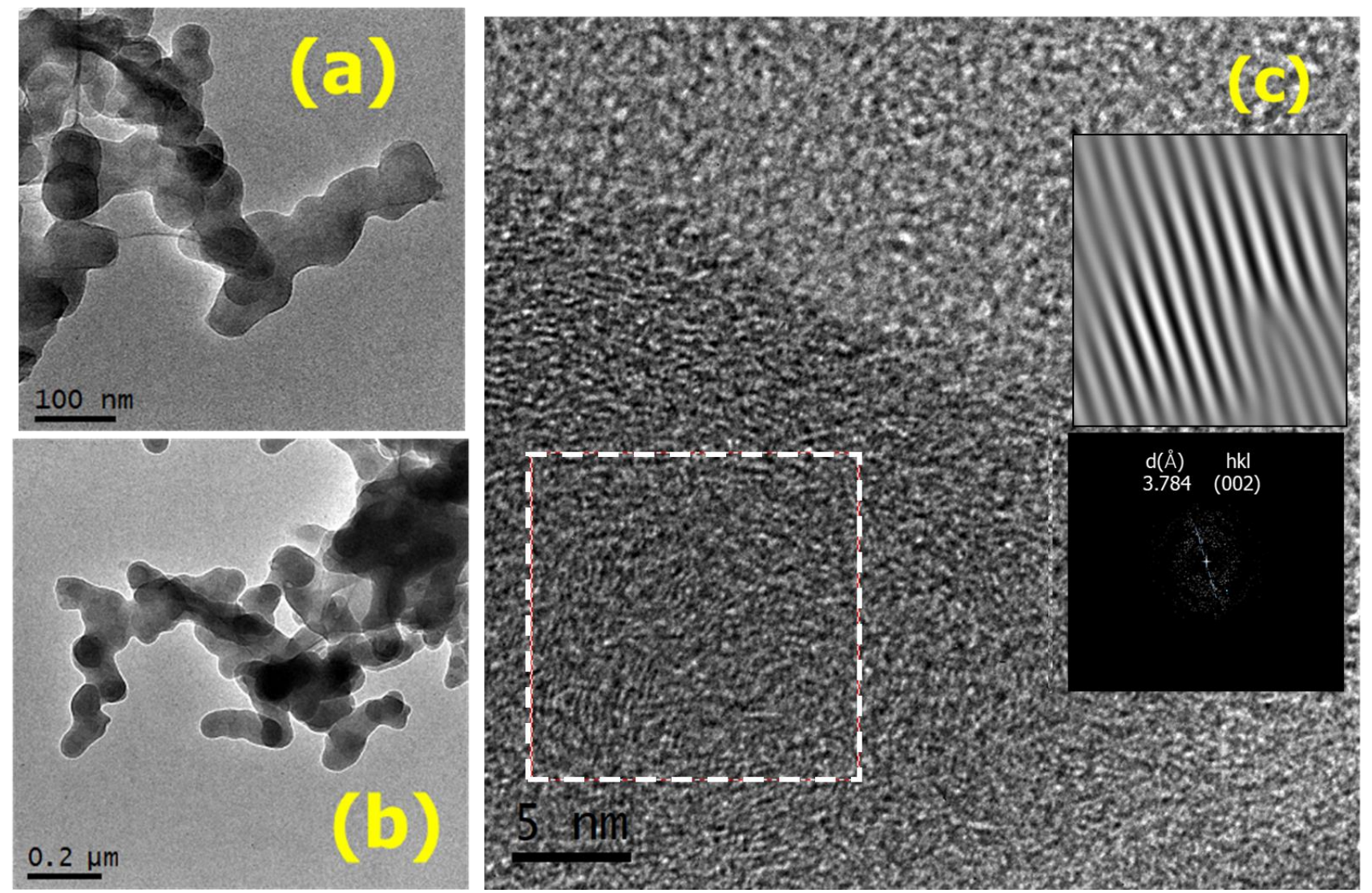

Figure 2. TEM: (a) and (b) Bright field of agglomerates of soot particles of forest biomass (c) HRTEM of soot particles, filtered high resolution area, and diffraction pattern FFT 